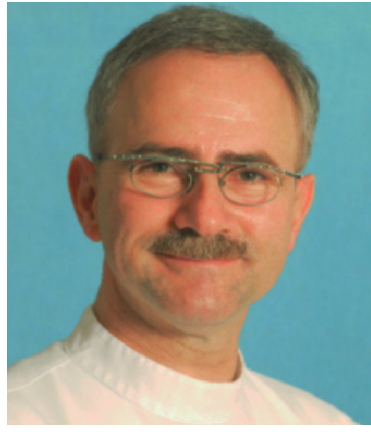

Dr DL. KAECH

\section{Symposium President message}

This 14th ArgoSpine Symposium is dedicated to essential and to less useful advances in medical technology. The question "Gadgets or future gold standards?" is on purpose provocative. How can we judge, or better predict, if a new spinal implant, or generally speaking a new invention, is going to significantly improve patients' outcome and therefore quality of life?

By inventing and manufacturing tools, man has over the last centuries contributed to the progress that finally resulted in the actual level of civilization. Creativity is a fundamental and artistic gift. Surgery requires creative and artistic skills, which however must rely on a solid scientific base. Visionaries like Leonardo da Vinci have already come up with many technical solutions to various problems and even made conceptual drawings, e.g. of a flying engine, that needed to be revised many times over the centuries to become a real gold standard of modern transportation.

Inventors of spinal implants, including of supporting instrumentation, have shown enthusiasm and thanks to their competitive mind, their success has often been commensurate with financial prosperity.

The temptation to offer "the latest gadget" because of its logical concept and of the expected financial reward, not to mention public reputation, has been leading to "excessive surgical indications", i.e., to some uncritical use of devices resulting finally in unsatisfactory results or even evident failures.

Some "modern tools and technologies" have been used over-enthusiastically, although they were not worth the money, for various reasons : a "prototype" was implanted rather than a well-conceived and studied device. Some surgeons were put under pressure by pseudo-informed patients with unrealistic expectations, based on a hasty, possibly advertising information from internet. Besides, the simple hope that a new tool could help in a "special" case, is not sufficient : if the pathology is clinically and radiologically not well understood, the final result can be a "failed back surgery syndrome".

By offering various lectures on different spinal implants followed bycritical interactive discussions, this upcoming 2010 ArgoSpine Symposium gives an opportunity to present the successes and failures, to define the gold-standards and to share the dilemmas in our daily practice. In this spirit, I would like to invite you to attend the next ArgoSpine Symposium in Paris on January 28 and 29, 2010. 